\title{
Linear-Analog Transformation Approach for Coupled Gas and Power Flow Analysis
}

\author{
Jesus Beyza ${ }^{a}$, Jose A. Dominguez-Navarro ${ }^{\text {a }}$, Jose M. Yusta ${ }^{\mathrm{a}, 1, *}$ \\ ${ }^{a}$ University of Zaragoza, Department of Electrical Engineering, C/ Maria de Luna 3, \\ 50018, Zaragoza, Spain
}

\begin{abstract}
In this paper, we present a methodology to analyze the integrated operation of coupled natural gas and electricity networks in steady-state. The interaction of the gas network with the electrical grid is modeled through mathematical equations that represent the energy exchange between the two infrastructures. The joint natural gas and power flow is solved using the linear-analog transformation (LAT) and the Newton-Raphson (NR) algorithm, respectively. Here, a unified solution framework of the two systems is presented using the previous proposed methods. The applicability of the methodology is illustrated using two case studies: IEEE-14 bus test system combined with a 16-node natural gas network and the IEEE-30 bus test system integrated with a 15-node natural gas network with 4 compressors. The proposed methodology proves to be useful for the assessment of coupled natural gas and electricity critical infrastructures. Keywords: Natural gas network, power systems, power flow analysis, linear-analog transformation.
\end{abstract}

\footnotetext{
* Corresponding author

Email addresses: jbbcia4@hotmail.com (Jesus Beyza), jadona@unizar.es (Jose A. Dominguez-Navarro), jmyusta@unizar.es (Jose M. Yusta)

${ }^{1}$ Phone: (0034) 976761922
} 


\section{List of Symbols}

$i \quad$ Index for the upstream node.

$j \quad$ Index for the downstream node.

$q_{G(i, j)} \quad$ Flow between pipeline $i$ and $j$.

$C_{(i, j)} \quad$ Conductivity of the pipeline between $i$ and $j$.

$s_{(i, j)} \quad$ Coefficient of the pipeline elevation.

$e \quad$ Pipeline roughness.

$p_{(i)} \quad$ Network pressure at point $i$.

$L_{(i, j)} \quad$ Pipeline conductivity of the linear-analog.

$T_{(i, j)} \quad$ Conductivity transform between the points $i$ and $j$.

$r_{(i, j)} \quad$ Pressure ratio between the points $i$ and $j$.

$H P \quad$ Horsepower of compression station.

$n_{s t} \quad$ Compression steps.

$n_{p} \quad$ Polytropic coefficient.

$Z_{a v} \quad$ Compressibility factor of the gas.

$\eta \quad$ Efficiency of the compressor station.

$T_{(i)} \quad$ Conductivity transform of the well $i$.

$k_{c} \quad$ Compressor coefficient.

$r_{c(i, j)} \quad$ Compression ratio of the station between $i$ and $j$.

$C_{c(i, j)} \quad$ Constant of the compressor station between $i$ and $j$.

$g_{k} \quad$ Natural gas taken from the network by the compressor station.

$k \quad$ Index for each iteration of LAT method.

Cf Natural gas consumption factor.

$S \quad$ Gas supplying at the corresponding node.

$D \quad$ Natural gas demand for domestic use and industrial.

$D_{g} \quad$ Natural gas demand for power generation.

$\Delta P_{(i)} \quad$ Active power mismatch of node $i$.

$P_{g e n}^{(i)} \quad$ Active power of generation at node $i$.

$P_{\text {load }}^{(i)} \quad$ Active power of load at node $i$.

$P_{c a l}^{(i)} \quad$ Calculated value of active power injection at node $i$. 


\begin{tabular}{|c|c|}
\hline$\Delta P$ & Vector of active power mismatch. \\
\hline$\Delta Q_{(i)}$ & Reactive power mismatch of node $i$. \\
\hline$Q_{g e n}^{(i)}$ & Reactive power of generation at node $i$. \\
\hline$Q_{\text {load }}^{(i)}$ & Reactive power of load at node $i$. \\
\hline$Q_{c a l}^{(i)}$ & Calculated value of reactive power injection at node $i$. \\
\hline$\Delta Q$ & Vector of reactive power mismatch. \\
\hline$V_{(i)}$ & Voltage magnitude at node $i$. \\
\hline$\Delta V$ & Vector of changes on the voltage magnitudes. \\
\hline$G_{(i, j)}$ & Conductance of the branch between $i$ and $j$. \\
\hline$B_{(i, j)}$ & Susceptance of the branch between $i$ and $j$. \\
\hline$\gamma_{(i)}$ & Angle of the voltage at node $i$. \\
\hline$\Delta \delta$ & Vector of changes on the angle magnitudes. \\
\hline$e_{(i)}$ & Amount of gas required by the generator of node $i$. \\
\hline$K_{0(i)}, K_{1(i)}, K_{2(i)}$ & Coefficient of gas consumption of generator $i$. \\
\hline$P_{G(i)}$ & Active power generation at node $i$. \\
\hline$K$ & Characteristic matrix of gas network. \\
\hline$P$ & Vector of gas network pressures. \\
\hline$S$ & Vector of gas supply and consumption. \\
\hline$O_{(i)}$ & Summation of the off-diagonal entries of matrix $K$. \\
\hline$s$ & Elevation coefficient. \\
\hline$S G_{G}$ & Specific gravity of the gas. \\
\hline$\Delta H$ & Pipelines elevation. \\
\hline$T_{a v}$ & Average temperature. \\
\hline$L_{e}$ & Pipeline equivalent length. \\
\hline$L$ & Horizontal pipeline equivalent length. \\
\hline$J$ & Jacobian matrix. \\
\hline$\sigma_{G}$ & Parameter of generalized gas model. \\
\hline$T_{s c}$ & Absolute temperature at standard conditions. \\
\hline$p_{s c}$ & Pressure at standard conditions. \\
\hline$f_{F}$ & Friction factor. \\
\hline
\end{tabular}




$\begin{array}{cl}d & \text { Internal diameter of the pipeline. } \\ \varepsilon & \text { Error on the estimation of gas network pressure. } \\ P_{G, \min } & \text { Minimum power of the generator. } \\ P_{G, \max } & \text { Maximum power of the generator. }\end{array}$

\section{Introduction}

The growing adoption of renewable energies as an alternative to conventional fuels for power generation has been accompanied by an increasing deployment of natural gas installations due to its capacity to deal with the unexpected variations of intermittent sources such as wind and solar photovoltaic generation [1. The interdependence between both systems lies mainly in the fact that natural gas-fired generators accounted for more than $40 \%$ of the operating electricity generating capacity in some countries. Thus, these networks cannot be considered as separated systems because operation of one can have an impact on the other.

This situation has established a very close relationship between power and gas systems from both financial and operational perspectives [2]. In this sense, the interaction between these systems for the study of their respective deregulated markets has gained relevance [3, 4], as well as for reliability studies [5], optimal control and scheduling [6], and critical infrastructures analysis [9, 10].

The focus of this work relies on the analysis of the integrated power and natural gas systems, which is a crucial process for most of the studies previously mentioned. On the one hand, power system simulation is performed including transmission lines, active and reactive power consumption, reactive power control, among other assets 11, 12. On the other hand, natural gas networks have been traditionally represented by pipelines and compressors, avoiding the effects of other elements such as valves and regulators [3, 13.

The computational simulation of both systems requires the solution of algebraic non-linear equations due to their complex behavior. In this regard, most of the methodologies available in the literature are based on Newton-Raphson 
method [14. In the case of power system analysis, voltages across the transmission or distribution systems are generally close to their nominal values, so that in many cases convergence of Newton method is observed [15]. However, in the case of natural gas networks, the solution of non-linear equations strongly depends on the initial approximation. These phenomena were extensively studied by Li et al. [16], who discussed the problem formulation in two different ways, taking into account the nodes (Newton-nodal method) and the loops (Newtonloop method) of the corresponding topology. The Newton-nodal formulation is based on the sum of flows at each node, while Newton-loop method uses the sum of the pressure drops around each loop. As loop formulation is almost quadratic due to the quadratic behavior of flow rates, Newton-loop method offers good convergence when compared to its counterpart. However, the loop to be analyzed has to be adequately selected, thus the formulation of the problem using loops becomes difficult. Otherwise, the use of numerical methods for the calculation of Jacobian matrix can ease the computational implementation of both methods by avoiding the required mathematical derivation in analytical form.

In other proposals that consider technical aspects in the operation of the coupled gas and electricity network, Martínez-Mares and Fuerte-Esquivel [11] incorporated the influence of the changes on natural gas temperature over the pipeline, which is an aspect that is not frequently considered to maintain the simplicity of the model. Erdener et al. [17] implemented a technique based on Newton-loop-node formulation combined with the Breadth First Search (BFS) algorithm. As the equation set under study is highly non-linear, BFS algorithm was used to find an initial solution to the algebraic problem. With the high interest on natural gas resources, specifically in urban areas, Shabanpour-Haghighi and Seifi [12] developed a model to incorporate a district heating network to the integrated power and gas system, taking into account the hydraulic as well as the thermal circuits on the balance equation. Wang et al. [18 developed the decoupled implicit method for efficient network simulation (DIMENS), which uses divide-and-conquer technique to increase the computational speed. DIMENS di- 
vides the gas network into sub-systems that are later fully analyzed. Dyachenko et al. 13 proposed the operator splitting technique based on the solution of a non-linear hyperbolic partial differential equation set to describe the hydrodynamic behavior of the gas system. As the most important characteristic, the technique is stable and accurate, as well as computationally efficient.

Recently, Ayala and Leong [19, 20, proposed the linear-analog concept in order to reduce the complexity of the algebraic equations used to evaluate the performance of natural gas networks. This method is based on applying linearanalog transformation (LAT) approach to the model of each asset of the gas network. Contrary to other proposals, in the LAT approach initial assumptions of pressures and flow rates are not necessary and only a set of algebraic equations that can be solved by standard numerical methods are required.

It can be noted that the works discussed above show that electricity and natural gas networks are well studied separately, however, a scope for improvement is observed in the development of techniques for analyzing the integrated operation of both critical infrastructure systems. This paper presents a methodology that allows to obtain the steady-state solution of coupled electricity and natural gas flows using the novel linear-analog method to solve the gas-flow problem. In the latter, the advantages of Newton's traditional approach using only nodal equations are preserved, but the formulation is simplified, the calculation of derivatives is eliminated and the computational cost is reduced [19, 20].

The rest of this paper is organized as follows: Section 2 describes in detail the mathematical models of the generalized gas-flow equation, pipes and compressors of the natural gas infrastructure using the linear-analog approach. Then, Section 3 presents the steady-state power system modeling with NewtonRaphson method. The simulation of the joint system is formulated and performed in Section 4, to be later implemented in two case studies presented in Section 5. Finally, the sum of the main conclusions of this work are discussed in Section 6. 


\section{Modeling of the natural gas network}

Fig. 1 presents a natural gas network with the components considered for the simulation, including supply and demand nodes, as well as the suction and discharge nodes of the compressor station.

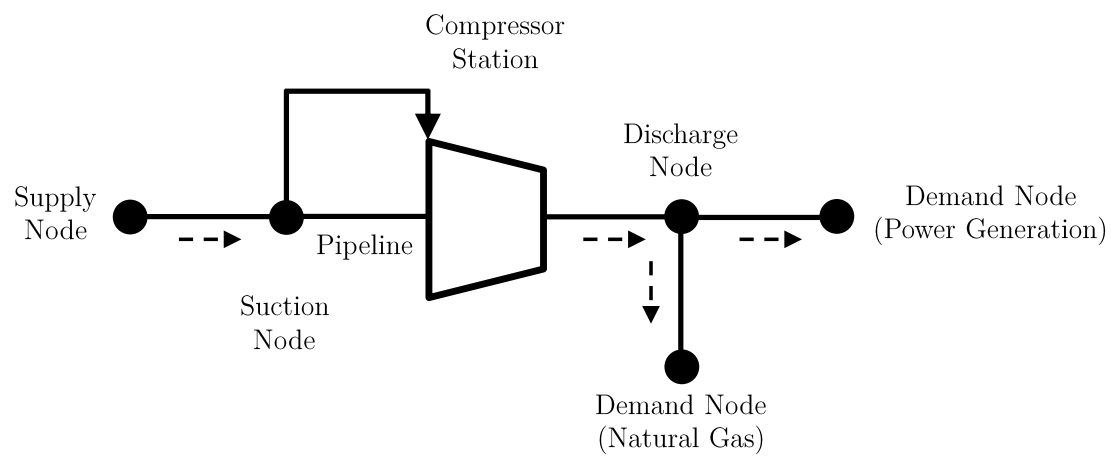

Figure 1: A simple natural gas network.

The reasoning behind LAT approach consists on substituting the non-linear formulation of system dynamics by an alternative model, simplifying according to some specific assumptions related to the behavior of the gas under laminar conditions. Therefore, this method has proved to be an ideal approach to solve the gas-load flow problem for natural gas infrastructures composed of pipes, compressors, supplies, among others. To find the solution of the gas system, the LAT method only uses nodal equations simplifying the computational calculation [19, 20.

\subsection{Linear-analog of the pipeline system}

Analyzing the behavior of natural gas network starts by establishing the expression that estimate the flow rate $q_{G(i, j)}$ through a pipeline $(i, j)$. A general form of such expression is presented in Eq. (1),

$$
q_{G(i, j)}=C_{(i, j)} \sqrt{p_{(i)}^{2}-e^{s_{(i, j)}} p_{(j)}^{2}}
$$

It can be noted the non-linear characteristic of Eq. 11, which increases the difficulty to accurately determine the pressure and flow across the system. 
In order to avoid this problem, LAT method uses a similar expression that is presented in Eq. 22.

$$
q_{G_{(i, j)}}=L_{i, j}\left(p_{(i)}-e^{\frac{s(i, j)}{2}} p_{(j)}\right)
$$

Where the inclination of the pipelines are considered by means of the elevation coefficient $s_{(i, j)}$, while the pressure conductivity is included by using $L_{(i, j)}=$ $T_{(i, j)} C_{(i, j)}$, which depends on the conductivity transform $T_{(i, j)}=\sqrt{1+\frac{2}{r_{(i, j)}-1}}$, obtained from the generalized gas flow model, and on the conductivity of the pipeline $C_{(i, j)}$.

Now, equating Eq. (1) and Eq. (2) as shown in Eq. (3) [19, 20],

$$
L_{i, j}\left(p_{(i)}-e^{\frac{s_{(i, j)}}{2}} p_{(j)}\right)=C_{(i, j)} \sqrt{p_{(i)}^{2}-e^{s_{(i, j)}} p_{(j)}^{2}}
$$

and introducing the pressure ratio defined as $r_{(i, j)}=\frac{p_{(i)}}{e^{\frac{s(i, j)}{2}} p_{(j)}}$, the linear representation of the quadratic expression shown in Eq. (3) is obtained in Eq. (4) [19, 20]:

$$
L_{(i, j)}^{2}\left(r_{(i, j)}-1\right)=C_{(i, j)}^{2}\left(r_{(i, j)}+1\right)
$$

Then, the corresponding linear equation system can be solved by means of standard techniques available in the literature. Here, $\left(T_{(i, j)}\right)>1$ due to the pressure ratio $r_{(i, j)}=\frac{p_{(i)}}{e^{\frac{s(i, j)}{2}} p_{(j)}}$, which leads to the pipeline conductivity $L_{(i, j)}>C_{(i, j)}$. Therefore, the calculation of gas flow through the network is an iterative process, starting with the assumption that $L_{(i, j)}=C_{(i, j)}$ or $2 C_{(i, j)}$, in order to obtain a first solution. Once the pressures have been initially estimated, the value of pressure ratio is then calculated, as well as the updated value of the pipeline conductivity of the respective linear-analog (the value of $L_{(i, j)}$ for the next iteration).

\subsection{The linear-analog of the compressor station}

Compression stations are conveniently installed to move the gas through the network and compensate the effects of friction of the pipelines, among other factors. Some compressor stations take gas from the network according to the 
amount of horsepower required, while others take power from an electrical system to boost the pressure.

The relationship between the power demanded by the station to increase the gas pressure, the compression stages, compressor efficiency and natural gas properties is presented in Eq. (5),

$$
H P=0.0857 \frac{n_{s t} \cdot n_{p}}{n_{p}-1} q_{G_{(i, j)}} T_{(i)} Z_{a v}\left(\frac{1}{\eta}\right)\left[\left(\frac{p_{(j)}}{p_{(i)}}\right)^{\frac{n_{p}-1}{n_{s t} \cdot n_{p}}}-1\right]
$$

This expression can be simplified by introducing the compressor coefficient shown in Eq. (6),

$$
k_{c}=0.0857\left(\frac{n_{s t} \cdot n_{p}}{n_{p}-1}\right) T_{(i)}\left(Z_{a v}\right)\left(\frac{1}{\eta}\right)
$$

Thus, gas flow through the compressor station can be obtained by re-ordering Eq. (5) and Eq. (6), which results in Eq. (7),

$$
q_{G(i, j)}=\frac{H P}{k_{c}\left[\left(r_{c_{(i, j)}}\right)^{\frac{n_{p}-1}{n_{s t} n_{p}}}-1\right]}
$$

The compression ratio of the compressor station located between the nodes $i$ and $j$ is defined according to Eq. (8),

$$
r_{c_{(i, j)}}=\frac{p_{(j)}}{p_{(i)}}
$$

Once the compression ratio has been defined, gas flow can be simplified and overwritten as presented in Eq. (9) 19, 20,

$$
q_{G_{(i, j)}}=C_{c_{(i, j)}} H P
$$

Where the variable $\left(C_{c_{(i, j)}}\right)$ is defined according to Eq. $10 p$,

$$
C_{c_{(i, j)}}=\frac{1}{k_{c}\left[\left(r_{c_{(i, j)}}\right)^{\frac{n_{p}-1}{n_{s t} \cdot n_{p}}}-1\right]}
$$

Regarding compressor stations based on gas absorption, the amount of gas drawn from the network $\left(g_{(k)}\right)$ can be estimated using Eq. (11),

$$
g_{(k)}=(C f) H P_{(k)}
$$


The factor $(C f)$ is strongly related to the natural gas calorific value. Regarding compressor stations powered by electricity, the corresponding amount of gas drawn is neglected.

\subsection{Balance of the natural gas system}

The balance of natural gas on each node of the system is shown in Eq. 12, which establishes that the total sum of gas entering and leaving the node must be equal to zero.

$$
\sum_{\substack{j \neq i \\ j \in i}}\left(L_{i j} \cdot\left(p_{i}-p_{j}\right)\right)+S_{i}-D_{i}-D_{g_{i}}-g_{(k)}=0
$$

Where $\left(L_{i j} \cdot\left(p_{i}-p_{j}\right)\right)$ is the flow rate of the pipelines adjacent to the node $i$, $S_{i}$ represents the natural gas inputs, $D_{i}$ are the domestic and industrial loads, $D_{g_{i}}$ are the natural gas demands for power generation and $g_{(k)}$ is the natural gas consumption by compressors. The latter is used only in the balance equation of the compressor input node.

\section{Modeling of the transmission power system}

As in the case of natural gas networks, power system behavior is modeled by using a set of non-linear equations represented in Eqs. 13 to 16 that are frequently solved using Newton-Raphson approach [11. Power balance of the system is determined through Eqs. (13) and (14) considering the respective value of voltage and angle at each node, as well as the power flows through the transmission lines.

$$
\begin{gathered}
\Delta P_{(i)}=P_{\text {gen }}^{(i)}-P_{\text {load }}^{(i)}-P_{\text {cal }}^{(i)}=0 \\
\Delta Q_{(i)}=Q_{\text {gen }}^{(i)}-Q_{\text {load }}^{(i)}-Q_{\text {cal }}^{(i)}=0 \\
P_{c a l}^{(i)}=\sum_{j \in i}\left\{V_{(i)}^{2} G_{(i, i)}+V_{(i)} V_{(j)}\left[G_{(i, j)} \cos \left(\theta_{(i)}-\theta_{(j)}\right)+B_{(i, j)} \sin \left(\theta_{(i)}-\theta_{(j)}\right)\right]\right\}
\end{gathered}
$$


$Q_{c a l}^{(i)}=\sum_{j \in i}\left\{-V_{(i)}^{2} B_{(i, i)}+V_{(i)} V_{(j)}\left[G_{(i, j)} \sin \left(\theta_{(i)}-\theta_{(j)}\right)-B_{(i, j)} \cos \left(\theta_{(i)}-\theta_{(j)}\right)\right]\right\}$

Next, the slack generator is chosen and the voltages and angles are calculated in order to solve the power flow problem. Finally, the non-linear equation system is solved by using Newton-Raphson approach.

\section{Modeling of the coupled gas and power grid}

Once the mathematical model of natural gas and power systems has been described, the interdependency model to study the interaction between them can be created. In this sense, the connection points of both infrastructures are on the gas fired power plants (GFPPs) and on the compressor units.

\subsection{Gas fired power plants (GFPPs)}

Energy conversion process of GFPP can be briefly described using Eq. 17) 21].

$$
e_{(i)}=K_{2_{(i)}} P_{G_{(i)}}^{2}+K_{1_{(i)}} P_{G_{(i)}}+K_{0_{(i)}}
$$

This expression defines the amount of gas demanded by the generation system to satisfy corresponding amount of power generation $P_{G}$. In other words, the gas consumption of each GFPP is related to the real power generation using Eq. (17).

\subsection{Compressor units}

Power consumption of compressor units is defined in Eq. (5), while those compressor units based on natural gas are modeled according to Eq. (11).

\subsection{Unified solution of natural gas and power flows}

The unified solution of the coupled electricity and natural gas flow is obtained when the electric and hydraulic models of both infrastructure systems 
are combined as described in the previous sections. The two networks are coupled with interdependent links that represent the flow exchange between the two systems. The power grid has gas fired power plants connected to their buses that are fed from determined nodes of the gas network. Similarly, the gas network has compressors that operate with external power supplied from certain buses of the electrical grid.

Fig. 2 presents the algorithm proposed to obtain the steady-state solution of coupled natural gas and electricity flow. In the first step of the algorithm of Fig. 2, the information required to simulate the power and natural gas infrastructures is collected assuming the bidirectional links described above. The study starts by solving the load flow problem in the electrical network using the NR method in order to calculate the voltages magnitudes and phase angles at all the buses in the infrastructure according to the defined power generations and loads. Next, active and reactive power flows through transmission lines are obtained. Since the power transmission losses in the electrical grid cannot be determined without first knowing the power flow, a slack generator with its defined voltage magnitude and phase angle is assigned to supply the power generation mismatch. In some instances, the slack generator could be coupled with the gas infrastructure. The power produced by the GFPPs are used to estimate the amount of natural gas required through the Eq. 177. Then, the demand for natural gas is incorporated as a load on the gas network. Next, the gas-load flow study is carried out using the LAT method incorporating the linear-analog equation of the compression stations. Here, consider that the amount of gas required for the power generation and the behavior of the mechanical and electrical compression stations are used to estimate the corresponding values of gas supplies and power demands, respectively. Finally, the process ends once the error become lower than a predefined tolerance.

All of the above is executed within an iterative framework to evaluate the joint operation of both coupled infrastructures. That is to say, in each step the mismatch of power generation of the slack bus is determined according to the gas supply and the electrical energy demanded by the coupled compressors. In 
this way, a more realistic and accurate simulation of the two interdependent infrastructures is obtained.

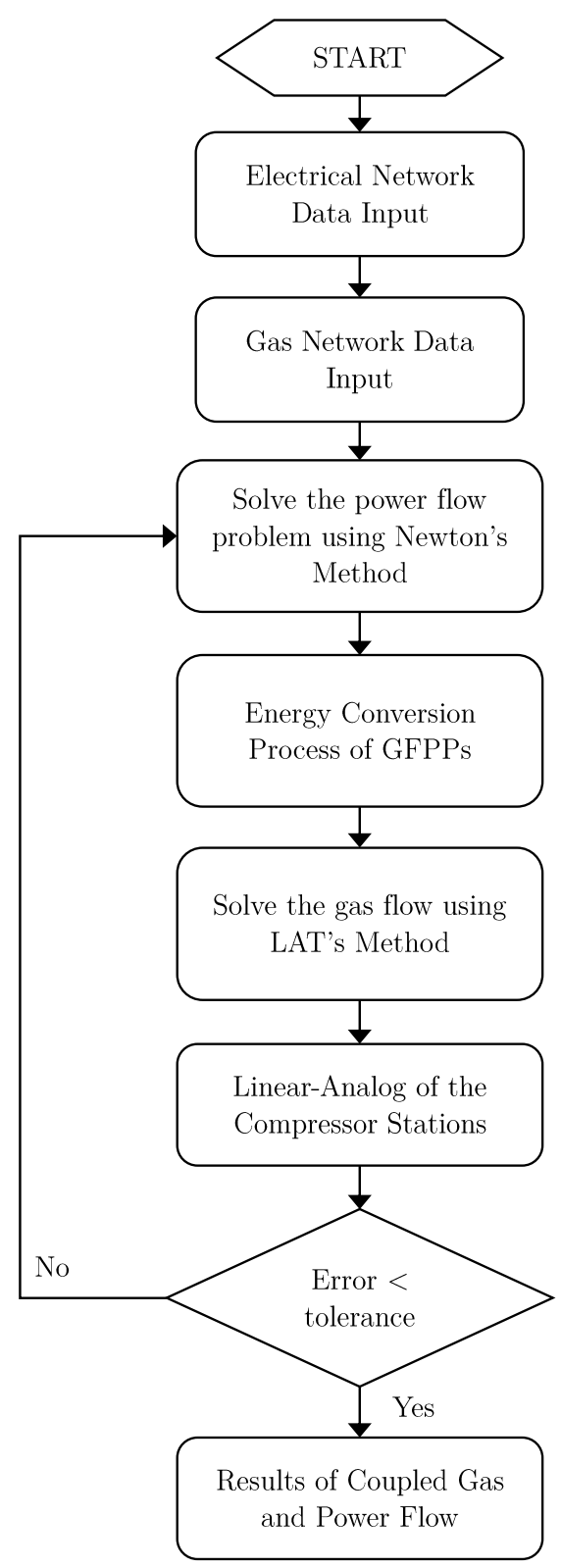

Figure 2: Flowchart of the proposed LAT-NR method. 
Power flow study is carried out by following the steps presented as follow:

Step 1. Create the Jacobian matrix of the system.

Step 2. Determine the changes on the voltage magnitudes $\left(V_{(i)}\right)$ and angles $\left(\theta_{(i)}\right)$, and update the corresponding values using Eq. (18),

$$
\left[\frac{\Delta \theta}{\Delta V}\right]=[J]^{-1} \cdot\left[\frac{\Delta P}{\Delta Q}\right]
$$

Step 3. Using the updated values of voltages, calculate the values of current $\left(I_{(i)}\right)$, active $\left(P_{(i)}\right)$ and reactive power $\left(Q_{(i)}\right)$. Then, calculate the corresponding active and reactive power mismatch.

Step 4. Repeat the steps previously explained until the active and reactive power mismatches becomes lower than a tolerance.

Step 5. At this step, natural gas required to supply the power generation can be calculated using Eq. (17).

Natural gas flow study can be carried out by following the steps presented as follow [19, 20]:

Step 1. Using the information related to the structure of the gas system, the coefficients of the pipeline elevation $(s)$ are calculated using Eq. 19,

$$
s=0.0375\left(\frac{S G_{G} \cdot \Delta H}{Z_{a v} \cdot T_{a v}}\right)
$$

While the equivalent length $\left(L_{e}\right)$ is calculated using Eq. 20),

$$
L_{e}=\left(\frac{e^{s}-1}{s}\right) L
$$

Note that $L_{e}=L$ for horizontal pipelines.

Step 2. The friction factor $\left(f_{F}\right)$ estimated according to a determined model (Weymouth, Panhandle, etc.) is used to calculate the conductivity $\left(C_{(i, j)}\right)$ as shown in Eq. 21,

$$
C_{(i, j)}=\frac{\sigma_{G}}{\sqrt{S G_{G} T_{a v} Z_{a v}}}\left(\frac{T_{s c}}{p_{s c}}\right) \sqrt{\frac{1}{f_{F}}}\left(\frac{d^{2.5}}{L_{e}^{0.5}}\right)
$$


Step 3. The compressor coefficients $\left(k_{c}\right.$ and $\left.C_{c_{(i, j)}}\right)$ are calculated using Eq. 6 and Eq. 10, while the conductivity of the linear-analog is estimated by means of $L_{(i, j)}=T_{(i, j)} C_{(i, j)}$.

Step 4. The characteristic matrix $(K)$ is built in order to create the algebraic system of Eq. 22, using the vector of gas supply and demand $(S)$.

$$
\underbrace{\left[\begin{array}{ccc}
-O_{(1)} & e^{\frac{s_{(1, j)}}{2} L_{(i, j)}} & \cdots \\
L_{(2, j)} & -O_{(2)} & e^{\frac{s_{(2, j)}}{2} L_{(2, j)}} \\
L_{(i, n)} & \cdots & -O_{(n)}
\end{array}\right]}_{K} \underbrace{\left[\begin{array}{c}
p_{(1)} \\
\vdots \\
p_{(n)}
\end{array}\right]}_{P}=\underbrace{\left[\begin{array}{c}
s_{(1)} \\
\vdots \\
s_{(n)}
\end{array}\right]}_{S}
$$

Step 5. The pressure and compressor ratios $\left(r_{(i, j)}\right.$ and $\left.r_{c_{(i, j)}}\right)$ are calculated in order to later obtain the values of the conductivity transforms using Eq. 23

$$
T_{(i, j)}=\sqrt{1+\frac{2}{r_{(i, j)}-1}}
$$

Step 6. This process is repeated until the error on the calculation of all the pressures around the network become lower than a predefined value $(\varepsilon)$. The amount of electrical power required by the compressor stations estimated as a result of the gas network analysis is used during the study of transmission power system, which is carried out according to [22].

To enhance the comprehension of the proposed method, two different systems are analyzed in the next section.

\section{Case studies}

To show the performance of the proposed model in the solution of coupled electricity and gas flow problem, in this paper two case studies are applied as described below:

1) a combined system consisting of the IEEE-14 bus network and a 16-node gas network.

2) a combined system consisting of the IEEE-30 bus network and a 15-node gas network with 4 compressors. 
Note that the case study 1) corresponds to a natural gas network that includes only pipes, while case study 2) corresponds to a natural gas network that considers pipes and compressors. The results are compared to the traditional NewtonRaphson approach.

\subsection{Case study 1}

The LAT-NR methodology is applied to analyze the coupled natural gas and electricity system consisting of a 16-node gas network and the IEEE-14 bus test system [23], shown in Fig. 3. The natural gas infrastructure is composed of 9 gas demands, 4 supplies and 21 pipes as shown in Tables1 1 and2. The diameters and lengths of pipes can be consulted in Table A.1. Node 1 of the gas network is selected as a slack node with a pressure equal to 547 PSIA. In the simulation an average gas temperature of $495^{\circ} \mathrm{R}$ is considered and the Weymouth generalized gas-flow equation with a compressibility factor of 0.9 and a specific gravity of 0.69 is used.

On the other hand, the electrical network has the power generations and demands presented in Table 1, where two GFPPs are considered operating on buses 2 and 3 fed from nodes 3 and 13 of the natural gas infrastructure, respectively. Similar to the gas network, Table 2 presents the connections of the transmission lines. The operation characteristics of the GFPPs with their gas consumption coefficients are presented in Table A.2. Additionally, the mismatch tolerances are $1^{-3}$ in the gas infrastructure and $1^{-8}$ in the electrical infrastructure.

The results in Table 1 indicate that the GFPPs located on buses 2 and 3 of the power system require a total gas flow of 33.7 MMSCFD to generate 178 MW. The reference node of the natural gas network provides 121 MMSCFD to satisfy the total demand of the system. Table 2 reports the flow rates in the pipes and power flows in the transmission lines obtained with the proposed methodology. Here, in order to validate the results achieved with the LAT-NR methodology, Table 2 shows the results of flow rates in the pipes obtained by the Newton-Raphson method. Likewise, the last column of Table 2 indicates the differences between the NR traditional method and the LAT-NR approach. 
In this case study, the total mean absolute deviation is 0.61 , which confirms the viability of the results achieved.

Fig. 4 shows the convergence of the method during the calculation of the flow rates through the pipes for Case 1. The iterative process was initialized under the assumption that $L_{(i, j)}=C_{(i, j)}$, which results in an overestimation of the gas flow during the first iterations of the iterative process $(k)$. However, it can be observed how the error decreases as the number of iterations increases.

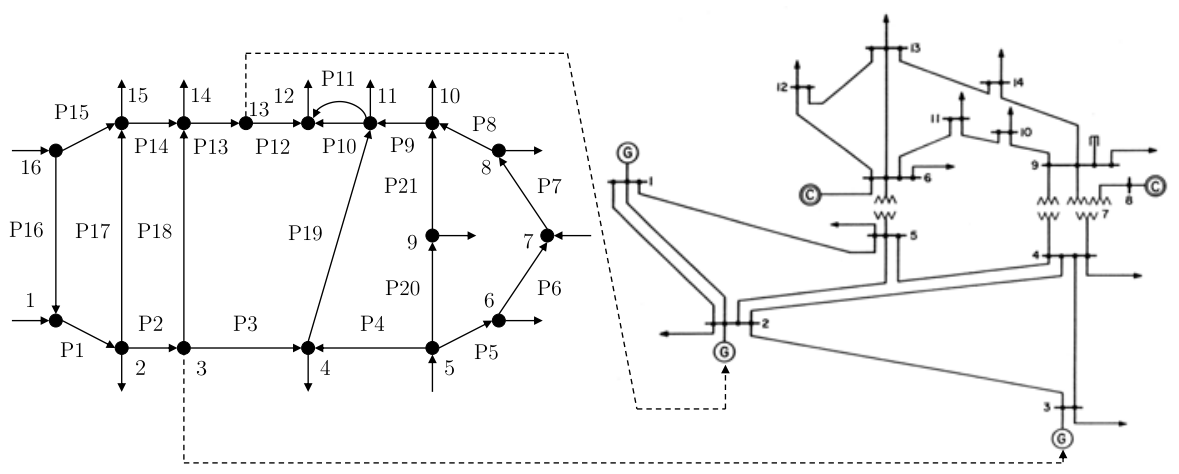

Figure 3: Natural gas network of 16 nodes coupled to power system of 14 buses. 
Table 1: Results of supplies, gas demands and power generation for Case 1.

\begin{tabular}{|c|c|c|c|c|c|c|c|}
\hline \multicolumn{5}{|c|}{ ELECTRICITY SUPPLY AND DEMAND } & \multicolumn{3}{|c|}{ NATURAL GAS SUPPLY AND DEMAND } \\
\hline \multirow[t]{2}{*}{ Bus } & \multicolumn{2}{|c|}{ Generation } & \multicolumn{2}{|c|}{ Load } & \multirow[t]{2}{*}{ Node } & \multirow{2}{*}{$\begin{array}{r}\text { Supply } \\
\text { (MMSCFD) }\end{array}$} & \multirow{2}{*}{$\begin{array}{r}\text { Demand } \\
(\text { MMSCFD) }\end{array}$} \\
\hline & $\mathrm{P}(\mathrm{MW})$ & Q (MVAr) & $\mathbf{P}(\mathrm{MW})$ & Q (MVAr) & & & \\
\hline 1 & 85.63 & 17.72 & 0.00 & 0.00 & 1 & 121.00 & 0.00 \\
\hline 2 & 95.00 & 8.91 & 21.70 & 12.70 & 2 & 0.00 & 4.70 \\
\hline 3 & 83.00 & -5.24 & 94.20 & 19.00 & 3 & 0.00 & $15.10(\mathrm{GFPP})$ \\
\hline 4 & 0.00 & 0.00 & 47.80 & -3.90 & 4 & 0.00 & 8.90 \\
\hline 5 & 0.00 & 0.00 & 7.60 & 1.60 & 5 & 151.80 & 0.00 \\
\hline 6 & 0.00 & 12.67 & 11.20 & 7.50 & 6 & 0.00 & 20.10 \\
\hline 7 & 0.00 & 0.00 & 0.00 & 0.00 & 7 & 192.60 & 0.00 \\
\hline 8 & 0.00 & 17.41 & 0.00 & 0.00 & 8 & 0.00 & 83.60 \\
\hline 9 & 0.00 & 0.00 & 29.50 & 16.60 & 9 & 0.00 & 11.20 \\
\hline 10 & 0.00 & 0.00 & 9.00 & 5.80 & 10 & 0.00 & 57.80 \\
\hline 11 & 0.00 & 0.00 & 3.50 & 1.80 & 11 & 0.00 & 60.80 \\
\hline 12 & 0.00 & 0.00 & 6.10 & 1.60 & 12 & 0.00 & 80.80 \\
\hline 13 & 0.00 & 0.00 & 13.50 & 5.80 & 13 & 0.00 & 18.60 (GFPP) \\
\hline \multirow[t]{3}{*}{14} & 0.00 & 0.00 & 14.90 & 5.00 & 14 & 0.00 & 64.20 \\
\hline & & & & & 15 & 0.00 & 50.70 \\
\hline & & & & & 16 & 11.10 & 0.00 \\
\hline TOTAL & 263.30 & 51.47 & 259.00 & 73.50 & & 476.50 & 476.50 \\
\hline
\end{tabular}


Table 2: Power flow and gas flow rate for Case 1.

\begin{tabular}{|c|c|c|c|c|c|c|c|c|c|c|c|c|}
\hline \multicolumn{7}{|c|}{ POWER FLOW } & \multicolumn{6}{|c|}{ GAS FLOW RATE } \\
\hline Line & $\begin{array}{c}\text { From } \\
\text { Bus }\end{array}$ & $\begin{array}{c}\text { To } \\
\text { Bus }\end{array}$ & $\begin{array}{c}\mathrm{P} \\
(\mathrm{MW})\end{array}$ & $\begin{array}{c}\mathrm{Q} \\
\text { (MVAr) }\end{array}$ & $\begin{array}{c}\mathbf{P} \\
(\mathrm{MW})\end{array}$ & $\begin{array}{c}\text { Q } \\
\text { (MVAr) }\end{array}$ & Pipe & $\begin{array}{l}\text { From } \\
\text { Node }\end{array}$ & $\begin{array}{c}\text { To } \\
\text { Node }\end{array}$ & $\begin{array}{c}\text { Gas Flow } \\
\text { NR } \\
\text { (MMSCFD) }\end{array}$ & $\begin{array}{c}\text { Gas Flow } \\
\text { LAT-NR } \\
\text { (MMSCFD) }\end{array}$ & Error \\
\hline L1 & 1 & 2 & 42.23 & 10.46 & -41.89 & -15.27 & P1 & 1 & 2 & 112.91 & 112.31 & 0.60 \\
\hline L2 & 1 & 5 & 43.40 & 7.26 & -42.45 & -8.65 & P2 & 2 & 3 & 83.57 & 82.40 & 1.17 \\
\hline L3 & 2 & 3 & 27.12 & 10.19 & -26.74 & -13.20 & P3 & 3 & 4 & -25.33 & -25.92 & 0.59 \\
\hline L4 & 2 & 4 & 47.69 & 0.37 & -46.47 & -0.30 & $\mathrm{P} 4$ & 5 & 4 & 142.71 & 142.12 & 0.59 \\
\hline L5 & 2 & 5 & 40.38 & 0.92 & -39.52 & -2.01 & P5 & 5 & 6 & -75.83 & -75.32 & 0.51 \\
\hline L6 & 3 & 4 & 15.54 & -11.04 & -15.31 & 10.31 & $\mathrm{P} 6$ & 7 & 6 & 95.93 & 95.42 & 0.51 \\
\hline L7 & 4 & 5 & -32.08 & 4.10 & 32.22 & -3.67 & $\mathrm{P} 7$ & 7 & 8 & 96.66 & 97.17 & 0.51 \\
\hline L8 & 4 & 7 & 29.29 & -9.71 & -29.29 & 11.55 & P8 & 8 & 10 & 13.06 & 13.57 & 0.51 \\
\hline L9 & 4 & 9 & 16.78 & -0.49 & -16.78 & 1.91 & P9 & 10 & 11 & 28.98 & 29.57 & 0.29 \\
\hline L10 & 5 & 6 & 42.15 & 12.72 & -42.15 & -8.65 & P10 & 11 & 12 & 17.51 & 17.93 & 0.42 \\
\hline L11 & 6 & 11 & 6.17 & 3.88 & -6.13 & -3.79 & P11 & 11 & 12 & 59.15 & 58.13 & 1.02 \\
\hline L12 & 6 & 12 & 7.64 & 2.57 & -7.57 & -2.42 & $\mathrm{P} 12$ & 13 & 12 & 4.13 & 4.72 & 0.59 \\
\hline L13 & 6 & 13 & 17.14 & 7.37 & -16.94 & -6.97 & $\mathrm{P} 13$ & 14 & 13 & 22.73 & 23.34 & 0.61 \\
\hline L14 & 7 & 8 & 0.00 & -16.96 & 0.00 & 17.41 & P14 & 15 & 14 & -6.87 & -5.66 & 1.21 \\
\hline L15 & 7 & 9 & 29.29 & 5.41 & -29.29 & -4.54 & P15 & 16 & 15 & 19.18 & 19.82 & 0.64 \\
\hline L16 & 9 & 10 & 6.40 & 3.87 & -6.38 & -3.83 & P16 & 1 & 16 & 8.08 & 8.72 & 0.64 \\
\hline L17 & 9 & 14 & 10.17 & 3.38 & -10.04 & -3.10 & P17 & 2 & 15 & 24.64 & 25.21 & 0.57 \\
\hline L18 & 10 & 11 & -2.62 & -1.97 & 2.63 & 1.99 & P18 & 3 & 14 & 93.80 & 93.21 & 0.59 \\
\hline L19 & 12 & 13 & 1.47 & 0.82 & -1.47 & -0.82 & P19 & 4 & 11 & 108.48 & 107.29 & 1.19 \\
\hline \multirow[t]{2}{*}{ L20 } & 13 & 14 & 4.91 & 1.99 & -4.86 & -1.90 & P20 & 5 & 9 & 84.92 & 84.99 & 0.07 \\
\hline & & & & & & & P21 & 9 & 10 & 73.72 & 73.79 & 0.07 \\
\hline
\end{tabular}



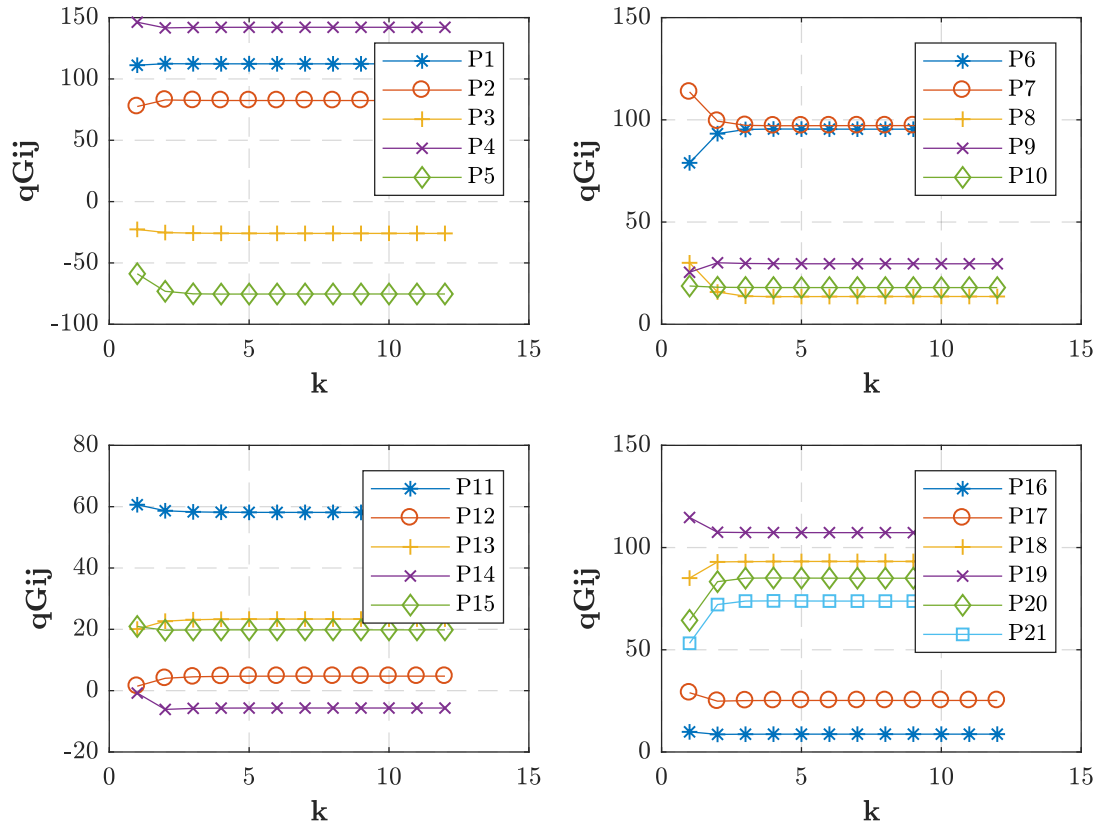

Figure 4: Convergence of flow rate $q G i j$ for Case 1.

\subsection{Case study 2}

The case study corresponds to a 15-node natural gas network with four compressors and the IEEE-30 bus test network [23]. The coupling between both infrastructures occurs through two GFPPs located on buses 1 and 2 as shown in Fig. 5. The gas consumption coefficients of the GFPPs are presented in Table B.1. On the other hand, the natural gas network consists of 15 nodes, 12 pipes, 3 demands, 2 supplies and 4 compressors. The diameters and lengths of the pipes are reported in Table B.2. In the gas system the Weymouth equation is considered with an average gas temperature of $520^{\circ} \mathrm{R}$ with a compressibility factor of 0.9. Unlike the case study 1 , the efficiency of pipes 9 and 12 is assumed to be 0.85 , while the resting pipes are assumed to be 0.9 . Node 1 of the gas network is considered as the slack node with a pressure equal to 1000 PSIA. The compression stations are operating with only one stage and a consumption factor of $199.92 \mathrm{SCFD} / \mathrm{HP}$. The tolerances in the iterative process are $1^{-3}$ in 
the gas infrastructure and $1^{-8}$ in the electrical infrastructure.

Table 3 shows the results of simulation of power generation, loads, supplies and gas demands of the coupled electricity and natural gas infrastructure. GFPPs on buses 1 and 2 produce 25.97 MW and 60.97 MW, respectively. These generators require 16.2002 MMSCFD of natural gas to provide such amount of power. On the other hand, the reference node of gas network injects 174.2916 MMSCFD of natural gas in order to achieve the system balance. In parallel, Tables 4 and 5 show the power flows and flow rates, as well as the natural gas consumption of the compression units, respectively. Moreover, the results are also reported between the LAT-NR methodology and the NR approach. Note that the mean absolute deviations are $0.25,11.54$ and 0.0024 , for the flow rates in pipes, horsepower (HP) and gas consumption in compressors. As can be seen, the LAT-NR technique offers a good solution on the simulation results of coupled natural gas and electricity flows.

In Figs. 6 and 7. the convergence of the iterative process for the calculation of the flow rate, HP and natural gas consumption for case 2 is presented. Identically to Case 1, the process was initialized under the assumption that $L_{(i, j)}=C_{(i, j)}$. Fig. 6 shows the different gas flows calculated in each iterative step $(k)$. Here, it can be observed that during the first iterations the gas flow in certain pipes varies drastically; however, as the number of iterations advances the gas flow stabilizes. In the same way, Fig. 7 a) presents the calculation of HP and Fig. 7b) shows the gas consumption for the previous calculations. Note that the natural gas consumption is a function of the compressor HP. 


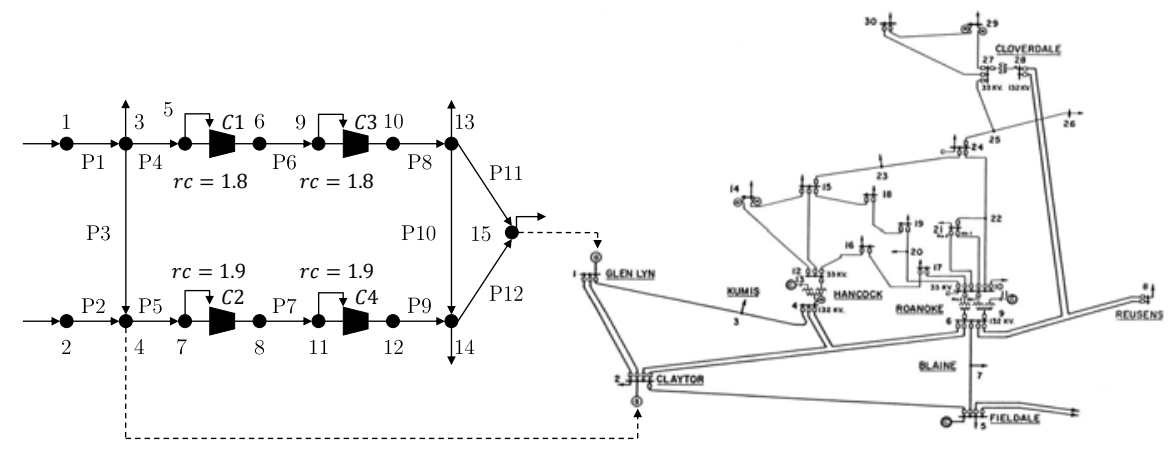

Figure 5: Natural gas network of 15 nodes coupled to power system of 30 buses.

Table 3: Results of supplies, gas demands and power generation for Case 2.

\begin{tabular}{|c|c|c|c|c|c|c|c|}
\hline \multicolumn{5}{|c|}{ ELECTRICITY SUPPLY AND LOAD } & \multicolumn{3}{|c|}{ NATURAL GAS SUPPLY AND DEMAND } \\
\hline \multirow[t]{2}{*}{ Bus } & \multicolumn{2}{|c|}{ Generation } & \multicolumn{2}{|c|}{ Load } & \multirow[t]{2}{*}{ Node } & \multirow{2}{*}{$\begin{array}{r}\text { Supply } \\
(\mathrm{MMSCFD})\end{array}$} & \multirow{2}{*}{$\begin{array}{r}\text { Demand } \\
\text { (MMSCFD) }\end{array}$} \\
\hline & $\mathbf{P}(\mathbf{M W})$ & Q (MVAr) & $\mathrm{P}(\mathrm{MW})$ & $\mathrm{Q}$ (MVAr) & & & \\
\hline 1 & 25.97 & -1.00 & 0.00 & 0.00 & 1 & 174.29 & 0.00 \\
\hline 2 & 60.97 & 32.00 & 21.70 & 12.70 & 2 & 164.80 & 0.00 \\
\hline 3 & 0.00 & 0.00 & 2.40 & 1.20 & 3 & 0.00 & 92.11 \\
\hline 4 & 0.00 & 0.00 & 7.60 & 1.60 & 4 & 0.00 & 11.11 (GFPP) \\
\hline 7 & 0.00 & 0.00 & 22.80 & 10.90 & 5 & 0.00 & 0.00 \\
\hline 8 & 0.00 & 0.00 & 30.00 & 30.00 & 6 & 0.00 & 0.00 \\
\hline 10 & 0.00 & 0.00 & 5.80 & 2.00 & 7 & 0.00 & 0.00 \\
\hline 12 & 0.00 & 0.00 & 11.20 & 7.50 & 8 & 0.00 & 0.00 \\
\hline 13 & 37.00 & 11.35 & 0.00 & 0.00 & 9 & 0.00 & 0.00 \\
\hline 14 & 0.00 & 0.00 & 6.20 & 1.60 & 10 & 0.00 & 0.00 \\
\hline 15 & 0.00 & 0.00 & 8.20 & 2.50 & 11 & 0.00 & 0.00 \\
\hline 16 & 0.00 & 0.00 & 3.50 & 1.80 & 12 & 0.00 & 0.00 \\
\hline 17 & 0.00 & 0.00 & 9.00 & 5.80 & 13 & 0.00 & 102.31 \\
\hline 18 & 0.00 & 0.00 & 3.20 & 0.90 & 14 & 0.00 & 102.57 \\
\hline 19 & 0.00 & 0.00 & 9.50 & 3.40 & 15 & 0.00 & $22.89+5.09(\mathrm{GFPP})$ \\
\hline 20 & 0.00 & 0.00 & 2.20 & 0.70 & & & \\
\hline 21 & 0.00 & 0.00 & 17.50 & 11.20 & & & \\
\hline 22 & 21.59 & 39.57 & 0.00 & 0.00 & & & \\
\hline 23 & 19.20 & 7.95 & 3.20 & 1.60 & & & \\
\hline 24 & 0.00 & 0.00 & 8.70 & 6.70 & & & \\
\hline 26 & 0.00 & 0.00 & 3.50 & 2.30 & & & \\
\hline 27 & 26.91 & 10.54 & 0.00 & 0.00 & & & \\
\hline 29 & 0.00 & 0.00 & 2.40 & 0.90 & & & \\
\hline 30 & 0.00 & 0.00 & 10.60 & 1.90 & & & \\
\hline TOTAL & 191.64 & 100.41 & 189.20 & 107.20 & & 339.09 & 336.09 \\
\hline
\end{tabular}


Table 4: Power flow and gas flow rate for Case 2.

\begin{tabular}{|c|c|c|c|c|c|c|c|c|c|c|c|c|}
\hline \multicolumn{7}{|c|}{ POWER FLOW } & \multicolumn{6}{|c|}{ GAS FLOW RATE } \\
\hline Line & $\begin{array}{c}\text { From } \\
\text { Bus }\end{array}$ & $\begin{array}{c}\text { To } \\
\text { Bus }\end{array}$ & $\begin{array}{c}\mathrm{P} \\
(\mathrm{MW})\end{array}$ & $\begin{array}{c}\mathrm{Q} \\
\text { (MVAr) }\end{array}$ & $\begin{array}{c}\mathbf{P} \\
(\mathrm{MW})\end{array}$ & $\begin{array}{c}\mathrm{Q} \\
\text { (MVAr) }\end{array}$ & Pipe & $\begin{array}{l}\text { From } \\
\text { Node }\end{array}$ & $\begin{array}{c}\text { To } \\
\text { Node }\end{array}$ & $\begin{array}{c}\text { Gas Flow } \\
\text { NR } \\
\text { (MMSCFD) }\end{array}$ & $\begin{array}{c}\text { Gas Flow } \\
\text { LAT-NR } \\
\text { (MMSCFD) }\end{array}$ & Error \\
\hline L1 & 1 & 2 & 10.89 & -5.09 & -10.86 & 2.17 & P1 & 1 & 3 & 174.29 & 174.29 & 0.00 \\
\hline L2 & 1 & 3 & 15.08 & 4.09 & -14.96 & -5.57 & P2 & 2 & 4 & 164.80 & 164.80 & 0.00 \\
\hline L3 & 2 & 4 & 16.07 & 5.21 & -15.89 & -6.66 & P3 & 3 & 4 & -42.14 & -41.78 & 0.36 \\
\hline L4 & 3 & 4 & 12.56 & 4.37 & -12.54 & -4.30 & P4 & 3 & 5 & 124.33 & 123.96 & 0.37 \\
\hline L5 & 2 & 5 & 13.79 & 4.51 & -13.68 & -6.03 & P5 & 4 & 7 & 111.55 & 111.91 & 0.36 \\
\hline L6 & 2 & 6 & 20.28 & 7.42 & -19.99 & -8.50 & $\mathrm{P} 6$ & 6 & 9 & 123.56 & 123.20 & 0.36 \\
\hline L7 & 4 & 6 & 22.50 & 11.38 & -22.43 & -11.12 & P7 & 8 & 11 & 110.80 & 111.16 & 0.36 \\
\hline L8 & 5 & 7 & 13.68 & 6.21 & -13.56 & -6.88 & P8 & 10 & 13 & 122.80 & 122.44 & 0.36 \\
\hline L9 & 6 & 7 & 9.27 & 3.17 & -9.24 & -4.02 & P9 & 12 & 14 & 110.06 & 110.42 & 0.36 \\
\hline L10 & 6 & 8 & 24.82 & 24.43 & -24.69 & -23.92 & P10 & 13 & 14 & 5.41 & 5.11 & 0.30 \\
\hline L11 & 6 & 9 & 5.79 & -3.36 & -5.79 & 3.46 & P11 & 13 & 15 & 15.08 & 15.02 & 0.06 \\
\hline L12 & 6 & 10 & 3.31 & -1.92 & -3.31 & 2.00 & P12 & 14 & 15 & 12.90 & 12.95 & 0.05 \\
\hline L13 & 9 & 11 & 0.00 & 0.00 & 0.00 & 0.00 & & & & & & \\
\hline L14 & 9 & 10 & 5.79 & -3.36 & -5.79 & 3.51 & & & & & & \\
\hline L15 & 4 & 12 & -1.67 & -2.02 & 1.67 & 2.04 & & & & & & \\
\hline L16 & 12 & 13 & -37.00 & -9.26 & 37.00 & 11.35 & & & & & & \\
\hline L17 & 12 & 14 & 5.39 & 0.88 & -5.35 & -0.80 & & & & & & \\
\hline L18 & 12 & 15 & 9.48 & -1.06 & -9.41 & 1.19 & & & & & & \\
\hline L19 & 12 & 16 & 9.26 & -0.10 & -9.18 & 0.28 & & & & & & \\
\hline L20 & 14 & 15 & -0.85 & -0.80 & 0.85 & 0.80 & & & & & & \\
\hline L21 & 16 & 17 & 5.68 & -2.08 & -5.65 & 2.15 & & & & & & \\
\hline L22 & 15 & 18 & 9.16 & 0.76 & -9.07 & -0.57 & & & & & & \\
\hline L23 & 18 & 19 & 5.87 & -0.33 & -5.85 & 0.38 & & & & & & \\
\hline L24 & 19 & 20 & -3.65 & -3.78 & 3.66 & 3.80 & & & & & & \\
\hline L25 & 10 & 20 & 5.92 & 4.62 & -5.86 & -4.50 & & & & & & \\
\hline L26 & 10 & 17 & 3.37 & 8.01 & -3.35 & -7.95 & & & & & & \\
\hline L27 & 10 & 21 & -2.23 & -11.67 & 2.28 & 11.77 & & & & & & \\
\hline L28 & 10 & 22 & -3.75 & -8.48 & 3.82 & 8.62 & & & & & & \\
\hline L29 & 21 & 22 & -19.78 & -22.97 & 19.87 & 23.16 & & & & & & \\
\hline L30 & 15 & 23 & -8.81 & -5.25 & 8.91 & 5.47 & & & & & & \\
\hline L31 & 22 & 24 & -2.10 & 7.80 & 2.18 & -7.68 & & & & & & \\
\hline L32 & 23 & 24 & 7.09 & 0.88 & -7.02 & -0.75 & & & & & & \\
\hline L33 & 24 & 25 & -3.86 & 1.77 & 3.89 & -1.71 & & & & & & \\
\hline L34 & 25 & 26 & 3.55 & 2.37 & -3.50 & -2.30 & & & & & & \\
\hline L35 & 25 & 27 & -7.44 & -0.66 & 7.50 & 0.78 & & & & & & \\
\hline L36 & 28 & 27 & -6.11 & -6.08 & 6.11 & 6.40 & & & & & & \\
\hline L37 & 27 & 29 & 6.17 & 1.68 & -6.08 & -1.51 & & & & & & \\
\hline L38 & 27 & 30 & 7.12 & 1.67 & -6.95 & -1.35 & & & & & & \\
\hline L39 & 29 & 30 & 3.68 & 0.61 & -3.65 & -0.55 & & & & & & \\
\hline L40 & 8 & 28 & -5.31 & -6.08 & 5.34 & 4.33 & & & & & & \\
\hline L41 & 6 & 28 & -0.77 & -2.70 & 0.77 & 1.75 & & & & & & \\
\hline
\end{tabular}


Table 5: Consumption of compressor stations for Case 2.

\begin{tabular}{|c|c|c|c|c|c|c|}
\hline $\begin{array}{l}\text { Compressor } \\
\text { stations }\end{array}$ & $\begin{array}{l}\text { HP } \\
\text { NR }\end{array}$ & $\begin{array}{c}\text { HP } \\
\text { LAT-NR }\end{array}$ & Error & $\begin{array}{c}\text { Gas consumption } \\
\text { NR } \\
\text { (MMSCFD) }\end{array}$ & $\begin{array}{c}\text { Gas consumption } \\
\text { LAT-NR } \\
\text { (MMSCFD) }\end{array}$ & Error \\
\hline $\mathrm{C} 1$ & 3821.61 & 3810.41 & 11.20 & 0.7640 & 0.7617 & 0.0023 \\
\hline $\mathrm{C} 2$ & 3727.24 & 3739.19 & 11.95 & 0.7451 & 0.7475 & 0.0024 \\
\hline C3 & 3798.13 & 3787.00 & 11.13 & 0.7593 & 0.7570 & 0.0023 \\
\hline \multirow[t]{2}{*}{$\mathrm{C} 4$} & 3702.35 & 3714.21 & 11.86 & 0.7401 & 0.7425 & 0.0024 \\
\hline & & TOTAL & & 3.0086 & 3.0089 & \\
\hline
\end{tabular}
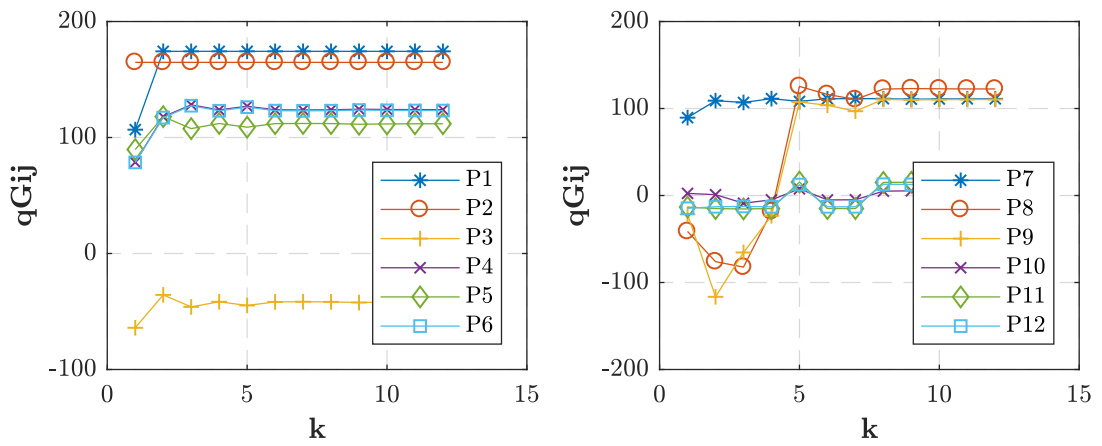

Figure 6: Convergence of flow rate $q$ Gij for Case 2.

a)

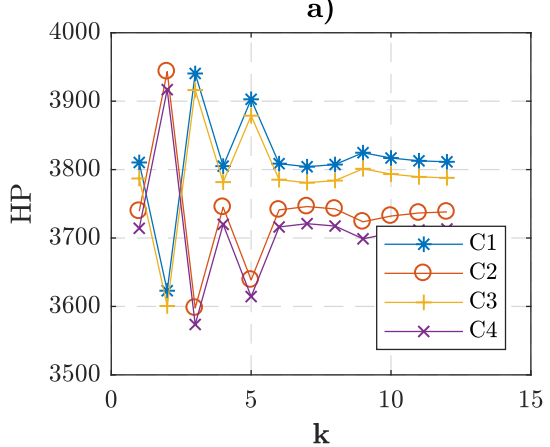

b)

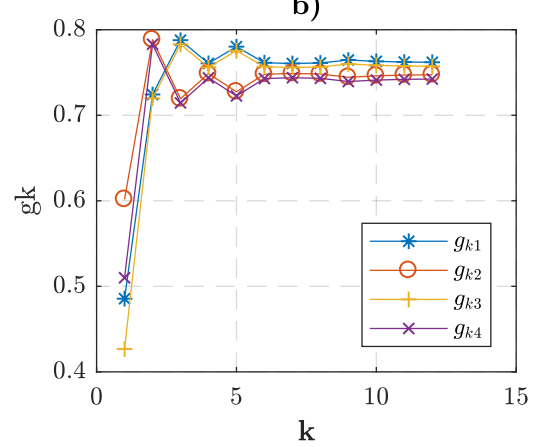

Figure 7: Convergence of HP and $g_{(k)}$ for Case 2. 


\section{Conclusions}

In this paper, a methodology has been presented to jointly analyze the coupled electricity and gas flow, where the existence of combined cycle power plants and compressors has been considered. The set of non-linear equations that represent the operation of the power system has been solved using Newton-Raphson (NR) method, while the solution of the gas nodal balance and flow rates in the pipelines and compressors on the gas network have obtained using the linearanalog approach (LAT). Two case studies have been presented to demonstrate the simplicity of the methodology proposed to analyze the interaction between gas and electricity systems. The results obtained with LAT have been verified against the Newton-Raphson method for gas networks, in order to confirm the solution reached, finding a good performance of the joint methodology applied LAT-NR. The application of the proposed approach allows the analysis of vulnerability and resilience of interdependent power and gas infrastructures. The authors are currently working in this area of research using the method described in this paper.

\section{Appendix A. Data for Case 1}

Table A.1: Diameters and lengths of pipes for Case 1.

\begin{tabular}{ccc|ccc|ccc}
\hline \hline Pipe & $\begin{array}{c}\text { Length } \\
\text { (miles) }\end{array}$ & $\begin{array}{c}\text { Internal } \\
\text { Diameter } \\
\text { (in) }\end{array}$ & Pipe & $\begin{array}{c}\text { Length } \\
\text { (miles) }\end{array}$ & $\begin{array}{c}\text { Internal } \\
\text { Diameter } \\
\text { (in) }\end{array}$ & Pipe & $\begin{array}{c}\text { Length } \\
\text { (miles) }\end{array}$ & $\begin{array}{c}\text { Internal } \\
\text { Diameter } \\
\text { (in) }\end{array}$ \\
\hline P1 & 37.49 & 30.95 & P8 & 13.32 & 15.5 & P15 & 17.76 & 12.25 \\
P2 & 13.88 & 33.35 & P9 & 15.43 & 15.5 & P16 & 46.36 & 12.25 \\
P3 & 31.26 & 33.35 & P10 & 10.31 & 14.18 & P17 & 34.84 & 15.44 \\
P4 & 9.13 & 31.65 & P11 & 19.28 & 25.17 & P18 & 30.59 & 25.47 \\
P5 & 15.99 & 19.5 & P12 & 21.47 & 12.25 & P19 & 41.90 & 25.37 \\
P6 & 35.52 & 19.5 & P13 & 11.05 & 12.25 & P20 & 16.55 & 23.44 \\
P7 & 30.18 & 17.5 & P14 & 5.70 & 12.25 & P21 & 22.75 & 23.44 \\
\hline \hline
\end{tabular}


Table A.2: Operation characteristics of GFPPs for Case 1.

\begin{tabular}{|c|c|c|c|c|c|}
\hline \multirow[t]{2}{*}{ Generator } & \multicolumn{3}{|c|}{$\begin{array}{l}\text { Coefficient of gas consumption } \\
\qquad\left(M M^{3} / M W\right)\end{array}$} & \multirow[t]{2}{*}{$\begin{array}{l}P_{G_{\min }} \\
(\mathrm{MW})\end{array}$} & \multirow[t]{2}{*}{$\begin{array}{l}P_{G_{\max }} \\
(\mathrm{MW})\end{array}$} \\
\hline & $K_{0}$ & $K_{1}$ & $K_{2}$ & & \\
\hline 2 & 0 & 0.00555 & 0 & 0 & 100 \\
\hline 3 & 0 & 0.00516 & 0 & 0 & 100 \\
\hline
\end{tabular}

\section{Appendix B. Data for Case 2}

Table B.1: Operation characteristics of GFPPs for Case 2.

\begin{tabular}{|c|c|c|c|c|c|}
\hline \multirow[t]{2}{*}{ Generator } & \multicolumn{3}{|c|}{$\begin{array}{l}\text { Coefficient of gas consumption } \\
\qquad\left(M M^{3} / M W\right)\end{array}$} & \multirow[t]{2}{*}{$\begin{array}{l}P_{G_{\min }} \\
(\mathrm{MW})\end{array}$} & \multirow[t]{2}{*}{$\begin{array}{l}P_{G_{\max }} \\
(\mathrm{MW})\end{array}$} \\
\hline & $K_{0}$ & $K_{1}$ & $K_{2}$ & & \\
\hline 1 & 0 & 0.00555 & 0 & 0 & 100 \\
\hline 2 & 0 & 0.00516 & 0 & 0 & 100 \\
\hline
\end{tabular}

Table B.2: Diameters and lengths of pipes for Case 2.

\begin{tabular}{ccc|ccc|ccc}
\hline \hline Pipe & $\begin{array}{c}\text { Length } \\
\text { (miles) }\end{array}$ & $\begin{array}{c}\text { Internal } \\
\text { Diameter } \\
\text { (in) }\end{array}$ & Pipe & $\begin{array}{c}\text { Length } \\
\text { (miles) }\end{array}$ & $\begin{array}{c}\text { Internal } \\
\text { Diameter } \\
\text { (in) }\end{array}$ & Pipe & $\begin{array}{c}\text { Length } \\
\text { (miles) }\end{array}$ & $\begin{array}{c}\text { Internal } \\
\text { Diameter } \\
\text { (in) }\end{array}$ \\
\hline P1 & 80.5 & 19.56 & P5 & 87.9 & 19.62 & P9 & 97.9 & 16.69 \\
P2 & 80.3 & 19.56 & P6 & 93.5 & 19.62 & P10 & 86.6 & 16.69 \\
P3 & 55.9 & 19.56 & P7 & 99.7 & 16.69 & P11 & 79.7 & 16.69 \\
P4 & 81.1 & 19.62 & P8 & 93.5 & 16.69 & P12 & 83.5 & 16.69 \\
\hline \hline
\end{tabular}

\section{Acknowledgements}

This work was supported by Ministerio de Economia y Competitividad, Spain, under grant ENE2016-77172-R, and CONACYT, Mexico, under grant 470886 . 


\section{References}

[1] D. Berry, Renewable energy as a natural gas price hedge: the case of wind, Energy Policy 33 (6) (2005) 799 - 807. doi:doi.org/10.1016/j.enpol. 2003.10.005.

[2] J. Gil, A. Caballero, A. J. Conejo, Power cycling: Ccgts: The critical link between the electricity and natural gas markets, IEEE Power and Energy Magazine 12 (6) (2014) 40-48. doi:10.1109/MPE.2014.2347631.

[3] C. Wang, W. Wei, J. Wang, L. Wu, Y. Liang, Equilibrium of interdependent gas and electricity markets with marginal price based bilateral energy trading, IEEE Transactions on Power Systems (2018) 1-14doi: 10.1109/TPWRS.2018.2796179.

[4] R. Chen, J. Wang, H. Sun, Clearing and pricing for coordinated gas and electricity day-ahead markets considering wind power uncertainty, IEEE Transactions on Power Systems 33 (3) (2018) 2496-2508.

[5] B. Odetayo, J. MacCormack, W. Rosehart, H. Zareipour, A chance constrained programming approach to integrated planning of distributed power generation and natural gas network, Electric Power Systems Research 151 (2017) 197 - 207. doi:doi.org/10.1016/j.epsr.2017.05.036.

[6] H. Üster, Ş. Dilaveroğlu, Optimization for design and operation of natural gas transmission networks, Applied Energy 133 (2014) 56-69. doi:10. 1016/j.apenergy.2014.06.042.

[7] B. Wang, M. Yuan, H. Zhang, W. Zhao, Y. Liang, An milp model for optimal design of multi-period natural gas transmission network, Chemical Engineering Research and Design 129 (2018) 122 - 131. doi:doi.org/10. 1016/j.cherd.2017.11.001

[8] Y. Wen, Q. Xiaobin, W. Li, X. Liu, X. Ye, Synergistic operation of electricity and natural gas networks via admm (2017) 1-1doi:10.1109/TSG. 2017.2663380 
[9] J. Jalving, K. K. Shrirang Abhyankar, V. M. Z. Mark Hereld, A graphbased computational framework for simulation and optimisation of coupled infrastructure networks, IET Generation, Transmission and Distribution 11 (2017) 3163-3176(13). doi:10.1049/iet-gtd.2016.1582.

[10] H. Su, E. Zio, J. Zhang, X. Li, A systematic framework of vulnerability analysis of a natural gas pipeline network, Reliability Engineering and System Safety 175 (2018) 79 - 91. doi:10.1016/j.ress.2018.03.006

[11] A. Martinez-Mares, C. R. Fuerte-Esquivel, A Unified Gas and Power Flow Analysis in Natural Gas and Electricity Coupled Networks, IEEE Transactions on Power Systems 27 (4) (2012) 2156-2166. doi:10.1109/TPWRS. 2012.2191984

[12] A. Shabanpour-Haghighi, A. R. Seifi, An integrated steady-state operation assessment of electrical, natural gas, and district heating networks, IEEE Transactions on Power Systems 31 (5) (2016) 3636-3647.

[13] S. A. Dyachenko, A. Zlotnik, A. O. Korotkevich, M. Chertkov, Operator splitting method for simulation of dynamic flows in natural gas pipeline networks, Physica D: Nonlinear Phenomena 361 (2017) 1 - 11. doi:doi. org $/ 10.1016 / j \cdot$ physd.2017.09.002

[14] S. Acha, C. Hernandez-Aramburo, Integrated modelling of gas and electricity distribution networks with a high penetration of embedded generation, in: CIRED Seminar 2008: SmartGrids for Distribution, no. 0032, IEE, 2008, pp. 28-28. doi:10.1049/ic:20080433

[15] A. H. El-Abiad, G. W. Stagg, Computer Methods in Power System Analysis, McGraw-Hill, 1968.

[16] Q. Li, S. An, T. W. Gedra, Solving natural gas loadflow problems using electric loadflow techniques, in: Proc. of the North American power symposium, 2003. 
[17] B. C. Erdener, K. A. Pambour, R. B. Lavin, B. Dengiz, An integrated simulation model for analysing electricity and gas systems, International Journal of Electrical Power and Energy Systems 61 (2014) 410 - 420. doi: https://doi.org/10.1016/j.ijepes.2014.03.052

[18] P. Wang, B. Yu, D. Han, D. Sun, Y. Xiang, Fast method for the hydraulic simulation of natural gas pipeline networks based on the divide-and-conquer approach, Journal of Natural Gas Science and Engineering 50 (2018) 55 63. doi:doi.org/10.1016/j.jngse.2017.11.017.

[19] L. F. Ayala H., C. Y. Leong, A robust linear-pressure analog for the analysis of natural gas transportation networks, Journal of Natural Gas Science and Engineering 14 (2013) 174-184. doi:10.1016/j.jngse.2013.06.008.

[20] C. Y. Leong, L. F. Ayala H., Hybrid Approach by Use of Linear Analogs for Gas-Network Simulation With Multiple Components, Oil and Gas Facilities 3 (01) (2013) 76-88. doi:10.2118/168225-PA.

[21] C. Unsihuay, J. Lima, a. D. Souza, Modeling the Integrated Natural Gas and Electricity Optimal Power Flow, 2007 IEEE Power Engineering Society General Meeting (2007) 1-7doi:10.1109/PES.2007.386124.

[22] R. D. Zimmerman, C. E. Murillo-Sanchez, R. J. Thomas, MATPOWER: Steady-State Operations, Planning, and Analysis Tools for Power Systems Research and Education, IEEE Transactions on Power Systems 26 (1) (2011) 12-19. doi:10.1109/TPWRS. 2010.2051168

[23] IEEE, IEEE Power Systems Test Case Archive (2018). URL https://www2.ee.washington.edu/research/pstca/ 